\title{
SIMULATION OF VERTICAL WATER FLOW THROUGH VADOSE ZONE
}

\author{
H. Garba ${ }^{1,}{ }^{*}$, M. Chiroma ${ }^{2}$ and S. D. Norman ${ }^{3}$ \\ 1, 2 Department of Civil EngineEring, Nigerian Defence ACADEmy Kaduna, Kaduna State, NigERIA \\ 3 DEPARTMENT OF GEOGRAPHY, NigERIAN DEFEnCE ACADEMy KAdUnA, KADUNA STATE, NIGERIA \\ E-mail addresses: ${ }^{1}$ garbaharuna84@gmail.com, ${ }^{2}$ zivility@yahoo.com, ${ }^{3}$ sdnorman@yahoo.com
}

\begin{abstract}
Simulation of vertical water flow representing the release of water from the vadose zone to the aquifer of surroundings within Nigerian Defence Academy $\left(34 \mathrm{~km}^{2}\right)$ for a sustainable ground water resources management was carried out using Advanced Simulation and Modelling of Urban Ground Water Management (UGROW model).Rainfall data, soil moisture and runoff coefficient are specified as input data into the model. Basic component of the vertical water balance (precipitation, leakages, evaporation and runoff) was observed. From the results, $4.0 \mathrm{~cm} /$ day of average leakage observed for the period 1991-2001 was the maximum leakage for the simulation.
\end{abstract}

Keywords: Vadose zone, Simulation, Groundwater, Unsaturation, Model

\section{INTRODUCTION}

The vadose zone which is often referred to as the zone of aeration or zone of unsaturation has its pore spaces usually containing air and water. The thickness of the zone extends from the land surface to the water table, the thickness can range from zero (0) at the surface to hundreds (100) meters to water table as common in arid regions [1]. The vadose zone is not always considered a major storage component of the hydrological cycle because it holds only a minute fraction of the earth's fresh water as investigated by [1]. Vadose zone flow according to [2] is fundamentally complicated by non-linearity and by interference of unsaturated hydraulic properties and also sensitive to material and hydraulic conditions. Predicting the movement of water flow rates and substrates removal within this zone has applications in fields of hydrology, agriculture and soil engineering [2] and is critical to infiltration, runoff, erosion, plant growth, aquifer recharge and discharge to surface [2]. The vadose zone according to [3] is an intrinsic part of the hydrological cycle essentially controlling the interrelationship between precipitation, infiltration, surface runoff, evaporation and ground water recharge. It also regulates the transfer of water from the land surface to ground water and vice versa. [3] reported further that the knowledge of the processes of transfer of water in the soil and techniques to foresee, predict and control water movement in the soil are important in the simulation of behaviour of water table. When precipitation reaches the ground it is partitioned into components of surface runoff and infiltration [4]. After water enters the soil column, it occupies part of the space within the soil mass as soil water. Recently, [5] observed that studies of unsaturated zone are increasingly motivated by concern about soil and ground water pollution from agricultural, industrial and municipal sources. Considerable progresses according to [5] have been obtained in the conceptual understanding and mathematical description of the vadose zone flow transport process. A variety of analytical and numerical models are now available to predict water flow and solute transport between land, surface and groundwater table [5]. The most popular according to [5] is the Richards equation for unsaturated flow and Fickian- based convectivedispersion equation for solute transport. These equations are respectively

$$
\begin{gathered}
C(h) \frac{\partial h}{\partial t}=\frac{\partial}{\partial z}\left[K(h) \frac{\partial h}{\partial z}-K(h)\right]+S \\
\frac{\partial(\rho s)}{\partial t}+\frac{\partial(\theta c)}{\partial t}=\frac{\partial}{\partial z}\left(\theta D \frac{\partial C}{\partial Z}-q c\right) \cdot+\emptyset
\end{gathered}
$$

Where $C$ is the soil water capacity, being the slope of the retention curve, $\theta(h), \theta$ is the volumetric water content, $\mathrm{h}$ is the soil water pressure head(being negative for unsaturated conditions), $t$ is time, $z$ is the distance from the soil surface downward, $\mathrm{k}$ is the hydraulic conductivity as a function of $\mathrm{h}$ and $\theta, \mathrm{s}$ is the solute concentration associated with the solid phase of 
the soil, $\mathrm{c}$ is the solute concentration of the fluid phase, $\rho$ is the soil bulk density, D is the solute dispersion coefficient, $s$ and $\emptyset$ are sources and sinks for water and solutes and $\mathrm{q}$ is the volumetric flux density.

Equations (1) and (2) according to [5] are formulated assuming isothermal soil conditions. Water flow in the unsaturated zone according to[6] has an indirect effect on the unsaturated soil hydraulic properties, hence $[7,8]$ provided a description of unsaturated zone processes requiring the incorporation of physical, chemical and biological processes taking place in the soil mass system.

The development and used of simulation models have increased the quantitative understanding of the main physical, chemical and biological processes within the unsaturated zone. The simulation of field scale processes according [9] requires considerable effort in quantifying spatial and temporal soil hydraulic parameters. [10] further adduced that the completeness of experimental data and the accuracy estimated model parameters may eventually become the critical factors determining site-specific simulations. A number of methods based on parameter estimation techniques have been introduced by $[10,11$. 12].

This study is there aimed at synergizing between model parameter and measured historical rainfall data as input into the Urban Ground Water Modelling system.

\section{METHODOLOGY}

\subsection{Materials}

2.1.1 The study Area: The Nigerian Defence Academy permanent site Afaka Kaduna lies between longitudes $7^{0} 12^{\mathrm{I}} \mathrm{E}$ to $7^{0} 3^{\mathrm{I}} \mathrm{E}$ of the Greenwich meridian and latitudes $10^{0} 36^{\mathrm{I}} \mathrm{N}$ to $10^{0} 42^{\mathrm{I}} \mathrm{N}$ of the equator. It occupies a landmass of about 34 square kilometres. The vegetation cover is Sudan Savannah type, characterized by scattered short trees, shrubs and grasses. Soil type is mostly loamy to sandy type. Substantial amount of clay is found also.

Kaduna State has two distinct seasons. The dry season lasts from November to Mid-April, and the rainy season which lasts between 5-6 months, starts from mid-April to November. The State has the tropical grass land vegetation known Guinea Savannah and Sudan Savannah. The climate condition in the state greatly influences activities of the people who are predominantly occupied in agriculture.

2.1.2 The Simulation Model: UGROW is a software tool developed for the management of the urban groundwater component of urban water systems. The software system was developed by the International Hydrological Program (UNESCO) [13] to raise awareness of the interaction between urban groundwater and other urban water systems, and to improve the capability of simulation models to represent this behaviour. Its main purpose is to allow the interaction of urban groundwater with other urban water systems to be visualized, demonstrated and quantified. To fulfil this task, vast amounts of data describing various urban water systems need to be stored and efficiently manipulated. This became feasible relatively recently with the rapid advent of powerful desktop computing resources that permit the design and development of a new generation of simulation models that can perform highly complex tasks. In UGROW, sophisticated, dynamic, simulation models are linked with GIS (Geographical Information Systems) to provide one of the most advanced urban groundwater simulation systems currently available [13].The model (Figure 1) is an integrated hydro informatics tool which contains Terrain, Geology and Grow components.

2.1.3 Data Used: The following meteorological and soil moisture data were used in forcing into the UNSAT (GROW) of the UGROW software to simulate the vadose flow: Rainfall, Evaporation, Run-off coefficient and soil moisture as presented in Table 1.

Table Summary of Input data (1996-2010)

\begin{tabular}{ccccc}
\hline Year & $\begin{array}{c}\text { Rainfall } \\
\text { Average(c } \\
\mathrm{m} / \text { day) }\end{array}$ & $\begin{array}{c}\text { Evaporation } \\
\text { Average(cm/day) }\end{array}$ & $\begin{array}{c}\text { Run-off } \\
\text { coefficient }\end{array}$ & $\begin{array}{l}\text { Soil } \\
\text { moisture } \\
\left(\mathrm{V}^{3} / \mathrm{v}^{3}\right)\end{array}$ \\
\hline 1996 & 0.34 & 0.48 & 0.30 & 0.12 \\
1997 & 0.36 & 0.49 & 0.30 & 0.12 \\
1998 & 0.29 & 0.51 & 0.30 & 0.12 \\
1999 & 0.36 & 0.49 & 0.30 & 0.12 \\
2000 & 0.31 & 0.51 & 0.30 & 0.12 \\
2001 & 0.40 & 0.50 & 0.30 & 0.12 \\
2002 & 0.37 & 0.50 & 0.30 & 0.12 \\
2003 & 0.45 & 0.51 & 0.30 & 0.12 \\
2004 & 0.38 & 0.50 & 0.30 & 0.12 \\
2005 & 0.27 & 0.49 & 0.30 & 0.12 \\
2006 & 0.25 & 0.51 & 0.30 & 0.12 \\
2007 & 0.24 & 0.50 & 0.30 & 0.12 \\
2008 & 0.24 & 0.51 & 0.30 & 0.12 \\
2009 & 0.33 & 0.51 & 0.30 & 0.12 \\
2010 & 0.35 & 0.51 & 0.30 & 0.12 \\
\hline
\end{tabular}

Source: Kaduna State Water Board [14]; Runoff coefficient data UNDP report [15].

Vol. 36, No. 4, October 2017 
Soil saturation data was obtained using soil samples collected from various locations of the NDA premises using the method of undisturbed sampling. Laboratory analysis was done according to BS 1377 [16] for the various samples and the average soil saturation was used. Initial soil saturation of 0.12 was used as obtained from samples collected from various locations in the NDA permanent site. Simulation parameters (soil moisture, surface runoff coefficient, evaporation and soil depth usually unto to $2.5 \mathrm{~m}$ are prescribed and applied).

\subsection{The model Simulation}

The UNSAT model simulates the migration of water through the 'topsoil' by solving the unsaturated flow equations such as the Richards equation ( $\mathrm{Eq} 1$ ), and also calculates the water balance terms. UNSAT also requires the input of meteorological data to calculate leakage from the unsaturated zone (aquifer recharge). Detailed records for daily rainfall and evaporation quantities available for the period 1996 to 2010 were used.

\subsubsection{Results and Discussion}

The simulation of the vadose zone water flow was carried with the input data as described in section three and the results obtained shown in Figure 2.

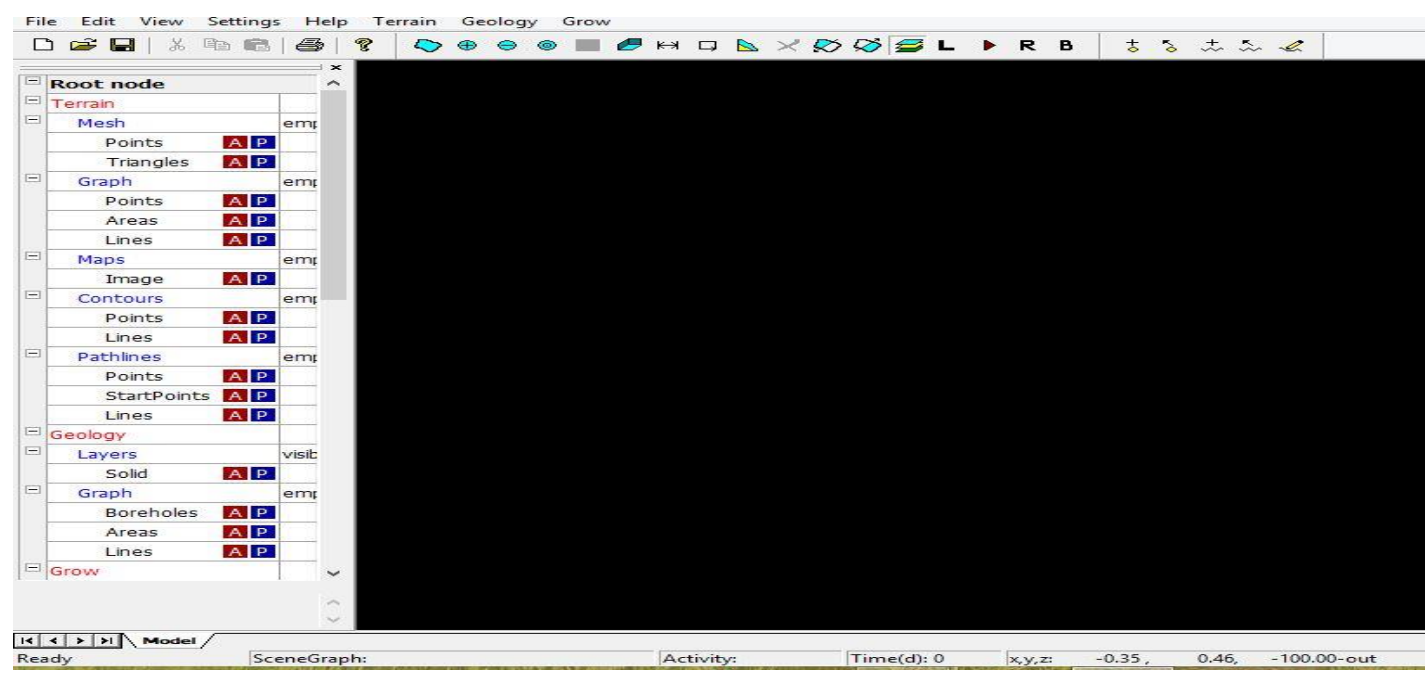

Figure 1: The GUI of UGROW

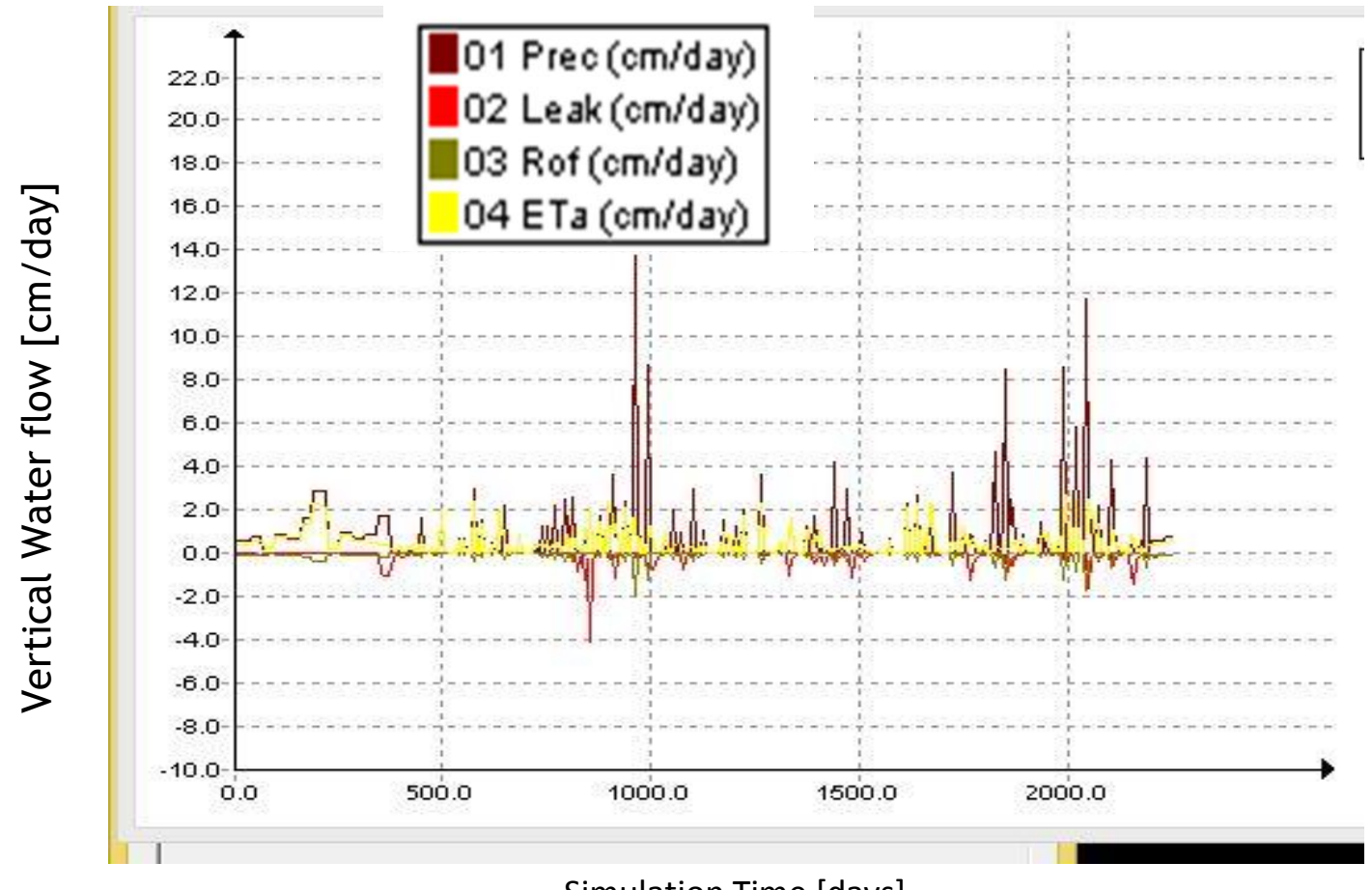

Simulation Time [days]

Figure 2: Unsaturated zone water balance of NDA Mando 


\section{DISCUSSIONS}

Figure 2 shows the components of the vertical water balance of average yearly leakages for fifteen years. The results considered five months of vertical water flow in a year from the month of May to September,(which are the months in which rain starts and ends in Kaduna), while the remaining months are considered to be the months in which abstraction from storage (aquifer) is normally experienced. For the simulation, $1.0 \mathrm{~cm} /$ day was observed for 1996-1998 representing 450 days, $4.0 \mathrm{~cm} /$ day was observed between 1999- 2001, $1.0 \mathrm{~cm} /$ day between $2002-2004,1.0 \mathrm{~cm} /$ day between 2005-2007 and $2.0 \mathrm{~cm} /$ day between 2008-2010. The highest observed value of $4.0 \mathrm{~cm} /$ day could be due to high duration low intensity rainfall within the period. Rainfall data was used to optimize the simulation process considering other specified parameters as fixed.

\section{CONCLUSION}

Simulation of vertical flow in vadose zone of Nigerian Defence Academy was carried out for a sustainable ground water resources management and development. The simulation model proves to be a reliable tool for the assessment of flow in unsaturated zone and recharge to aquifer. However, an increase or decrease in the value of other specified input data such as runoff coefficient due to paved surfaces will lead to increase runoff and reduced infiltration.

\section{REFERENCE}

[1] Nimmo. J. R. Vadose Water In . Likens, G. E. ed. Encyclopaedia of Inland Water: Oxford UK. Elsevier .V.I 2009 pp 776-777.

[2] Castanheira. P. J. and Santos .F.L A simple numerical analyses software for predicting water table height in subsurface drainage. Springer Science + Business Media.B.V.2009. Irrig. Drainage Syst. DOI 10.1007/s10795-009-9079-5

[3] Miller K. A.. Peak Flow Characteristics of Wyoming Streams: US Geological Survey Report. Water Resources Investigation 2003-4107. Wyoming Department of Transportation Cheyeme Wyoming.

[4] Yu.Z Hydrology/Modelling and Prediction. Elsevier Science Ltd, 2002.
[5] Richard L.A.. "Capillary Conduction of Liquids through Porous Media". PhD Thesis. Cornell University. Physics. 1(5). 318-333: Bibcode: 1931. Physic....1...318r. doi:10:1063/1.1745010.

[6] M. TH. Van Genuchen; "Recent progress in modelling water flow and chemical transport in unsaturated flow zone, Hydrological interactions between atmosphere, soil and vegetation" "Proceeding of the Vienna Symposium", August 1991 IAHS Publ. no 204. 1991

[7] Hopmans J. W. and Dane J.H; Temperature dependence of soil hydraulic properties. Soil. Sci. Soc AM Journal 50(1), 4-19; 1986.

[8] Hansen S W, Jensen H. E, Nelsen NE and Svendsen $\mathrm{H}$, Simulation of nitrogen dynamics in the soil water plant system, using Danish Simulation model. DAISY; IAHS, Publ no 2041991.

[9] Kuchment LS and Startsera ZP; Modeling moisture transport in the soil canopy-atmosphere system,IAHS Publ.no 2041991.

[10] Oatrawski M. W.; The effect of data accuracy on results of soil moisture modelling, IAHS Publ. no 2041991.

[11] Wagner B. J. and Gorelick SM.“A Statistical method for estimating transport parameters, theory and applications to one- dimensional adversivedispersive system". Water Resources. RES 22(8) 1303-1315. 1988.

[12] Kool J. B. and Parker J. C."Analysis of inverse problems for transient unsaturated flow", Water Resources RES 24(6) 817-830, 1988.

[13] Mishra S and Parker JC; Parameter estimation for coupled unsaturated flow and transport. Water Resources RES 25(3) 385-3961989.

[14 Pojrajac D and Howard K. Advanced Simulation and Modelling of Urban Ground Water Management UGROW: CRC Press. Taylor and Francis Group. Boca Raton London. UNESCO Publishing. 2010.

[15] Kaduna State Water Board. Hyro-Meteorological Section Annual Report. 1989.

[16] United Nations Development Programme; Kaduna Sewerage and Drainage Project UNDP Project NIR/75/101: Master Plan Design Criteria 1978.

[17] British Standard 1377. "Methods of Test for Civil Engineering Purposes". British Standard Institute London England. 1990. 